\title{
The sources of aggregate profitability: Marx's theory of surplus value revisited
}

\author{
Peter Flaschel ${ }^{*}$ \\ Department of Business Administration and Economics, Bielefeld University, Germany
}

\author{
Nils Fröhlich* \\ Department of Economics, Chemnitz University of Technology, Germany \\ Roberto Veneziani* \\ School of Economics and Finance, Queen Mary University of London, UK
}

This paper provides an empirical analysis of Marx's theory of exploitation built on the standard interpretation of the value of labour power. The relationship between the aggregate value rate of profit and the aggregate price rate of profit is studied and it is shown that the two rates coincide up to negligible deviations by using flow as well as stock matrix data for the German economy (1991-2000). This suggests that the main determinants of the value rate - namely absolute and relative surplus value, as well as technical progress affecting the value of the aggregate capital stock - may help to understand the dynamics of the aggregate market rate of profit.

Keywords: labour values, profit rates, input-output models

JEL codes: $B 51, C 67, D 46, D 57$

\section{INTRODUCTION}

One of the key contributions of recent debates in value theory and in exploitation theory is the idea that there is no 'transformation problem' to be solved in Marx's labour theory of value. Labour values are not meant to provide an explanation of classical production prices. Yet a coherent account of values and the labour content of goods can be provided that is able to inform the empirical and theoretical analysis of the basic laws of capitalism, of the exploitative nature of capitalist relations of production, and of the determinants of the key magnitudes of capitalist economies, especially from a macroeconomic perspective. ${ }^{1}$ Moreover, all of the main recent approaches emphasise the essential monetary dimension of the economy, and the relation between actual money magnitudes and their labour counterparts. From this perspective, an attempt

* We are grateful to participants of the FMM 2011 conference (Berlin) for comments on an earlier version of the paper. Special thanks go to two anonymous referees of this journal for detailed suggestions. The usual disclaimer applies.

1. See the classic contributions by Duménil (1980), Foley (1982), Flaschel (1983) and, more recently, Mohun (2004), Yoshihara (2010), Veneziani and Yoshihara (2011; 2012).

Received 16 March 2012, accepted 17 March 2013 
to transform labour values into production prices is theoretically dubious and empirically meaningless. These approaches provide logically consistent interpretations of Marxian value theory and the foundations for a rigorous empirical analysis of capitalist economies. However, the emphasis on macroeconomic relations and on monetary magnitudes leaves open the issue of the role of labour values and, apart from normative analysis, it is unclear whether labour magnitudes are of central theoretical relevance.

This paper aims to show that a system of labour accounts can be developed which is independent from money accounts and which provides theoretically and empirically relevant insights on observed phenomena in capitalist economies. To be precise, we analyse dual interpretation of Marx's theory of profitability whose structure is conceptually analogous to that of a System of National Accounts (henceforth, SNA), in which real magnitudes form a dual structure with respect to prices and quantities. A real SNA is designed to promote an understanding of the key processes driving the motion of nominal magnitudes. Analogously, Marx's labour value aggregates were designed as the essential elements of an understanding of what happens underneath the surface of the process of capital accumulation. In a recent paper, Flaschel et al. (2012b) have shown that the standard measures of labour content used in the input-output literature, the classic Marxian labour values, represent the only sound labour productivity indices. Further, by using the standard Marxian labour values, they have provided a general proof of the law of decreasing labour content - arguably one of the key laws of capitalist accumulation - by demonstrating that profitable technical change that tends to replace living labour with capital (that is, capital-using labour-saving technical change) tends to decrease the labour content of commodities. In this paper, we argue that standard labour values provide important insights on one of the most important issues in Marxian economics, namely the determinants of the general, or economy-wide, rate of profit. And Marx had a clear interest in demonstrating that his labour theory of value explained the key variables determining profitability. Concerning the value and price of intermediate inputs, however, he wrote:

[i]t is necessary to remember this modified significance of the cost-price, and to bear in mind that there is always the possibility of an error if the cost-price of a commodity in any particular sphere is identified with the value of the means of production consumed by it. (Marx 1954: 165)

This paper shows that this logical error in the comparison of value and price magnitudes may be empirically irrelevant and that the key insights of the Marxian theory of exploitation and of the profitability of a capitalist economy are valid.

In Section 2, the basic analytical framework is presented. We adopt a standard input-output theoretic approach. Our model is rather general in that it includes matrices of capital depreciation and capital advanced for production in every sector, as suggested by Bródy (1970), and it allows for imported inputs and heterogeneous labour. We define labour values on the basis of the United Nations' SNA: as in standard input-output theory, labour values correspond to the total labour costs in the production of goods. In Section 3, the economy-wide price and value rates of profit are defined and analysed at the theoretical level. The price rate of profit is standard and needs no further comment. In this paper we define the value rate of profit by focusing on the standard notion of the value of labour power as the labour embodied in the workers' consumption bundle. However, our theoretical focus is on class relations and profitability, rather than individual consumption, and so we abstract from savings and focus on a notional consumption bundle that captures workers' capacity to consume. 
We identify three main determinants of the value rate of profit: the creation of absolute and relative surplus value, and technical change and accumulation (via their effects on the value of the total capital stock). We also show that differences between the two rates depend on the differences between the wage share and the (standard) value of labour power, and between the price and value measures of the total capital stock. In Section 4, the relation between price and value magnitudes is analysed from an empirical viewpoint, based on a novel input-output dataset on the German economy (1991-2000) constructed by Kalmbach et al. (2005). Although labour values and prices are quite different at the sectoral level, these differences cancel out on aggregate and the economy-wide value and price profit rates coincide up to negligible deviations. To be sure, this does not allow us to draw any robust inferences about causality, yet the correlation between the two rates is so strong and robust as to suggest that a common set of mechanisms is at play. Theoretically, we would argue that, in line with Marx's theory of exploitation, the creation of absolute and relative surplus value are the essential sources of profitability in a capitalist economy, together with changes in the value of the total capital stock. Section 5 concludes.

\section{THE SNA APPROACH TO MARXIAN LABOUR VALUES}

We adopt the standard modelling framework and notation common in input-output theory. We consider an economy with $m$ goods produced in $m$ sectors. In any given period, technology and demand in the economy are described as follows: $A$ is the $m \times m$ matrix of intermediate inputs, $l$ is the $1 \times m$ vector of direct labour inputs, $x$ is the $m \times 1$ vector of gross output, $y$ is the $m \times 1$ vector of final demand. ${ }^{2}$ In addition, we follow Bródy's (1970) seminal approach to fixed capital and identify the $m \times m$ matrices of capital advanced, $K$, and of capital depreciation, $D$. The standard definition of Marxian labour values in this context is then given by:

$$
v=v(A+D)+l, \text { that is, } v=l(I-(A+D))^{-1} .
$$

Hence, for each sector $j=1, \ldots, m$, the labour value $v_{j}$ of the good produced in $j$ depends on direct labour and on the consumption of labour imputed to both intermediate inputs and depreciated capital equipment. As is well known, some weak conditions on the matrix $A+D$ are sufficient to guarantee that the previous equation has a well-defined solution and the vector $v$ is strictly positive whenever the vector $l$ is. Labour values play a prominent role in Marxian economics and have been at the centre of vast debates on their role and significance. However, the vector $v$ is also important in standard inputoutput analysis, and we believe that the relationship between Marxian economics and the input-output approach is deeper than a mere formal similarity. It is indeed of central importance, and it suggests a theoretical and empirical reconsideration of labour values. The SNA approach to the measurement of total labour costs in production is most clearly presented in Richard Stone's formulation of the UN's SNA (United Nations 1968), which contains various theoretically rigorous definitions of labour productivity. Consider, for example, technical change in a simple economy with circulating capital only. Let $(A, l),\left(A^{*}, l^{*}\right)$ denote, respectively, technology in the base and in the current period, and let $v, v^{*}$ be the associated vectors of total labour costs. Let $x^{*}$ denote a vector

2. Because the data refer to a specific time period, all variables should be dated, however we omit time subscripts for the sake of notational simplicity. 
of gross output producible with the new technology. In the UN's SNA, the change in labour productivity between the two periods, $\Lambda^{*}$, is defined as follows (United Nations 1968: 69):

$$
\Lambda^{*}=\frac{l(I-A)^{-1}\left(I-A^{*}\right) x^{*}}{l^{*} x^{*}}=\frac{v\left(I-A^{*}\right) x^{*}}{v^{*}\left(I-A^{*}\right) x^{*}} .
$$

Note that the previous definition holds for any $x^{*}$ and that by definition the following relation holds between gross and net output $y: A^{*} x^{*}+y=x^{*}$. Therefore, setting $y=$ $(1,0, \ldots, 0)^{\prime}, x^{*}$ represents the activity vector that produces one unit of commodity 1 as net product and the SNA equation of the change in labour productivity becomes:

$$
\Lambda^{*}=\frac{v y}{v^{*} y}=\frac{v_{1}}{v_{1}^{*}} .
$$

This is just the relative change in Marx's index of labour productivity, $\frac{1 / v_{1}^{*}}{1 / v_{1}}$, as considered in the following quotation:

In general, the greater the productiveness of labour, the less is the labour-time required for the production of an article, the less is the amount of labour crystallised in that article, and the less is its value; and vice versa. ... The value of a commodity, therefore, varies directly as the quantity, and inversely as the productiveness, of the labour incorporated in it. (Marx 1954: 48)

The pragmatism of national accounting, when based on a sound input-output methodology, thus leads to the Marxian measure of labour productivity, although this was not in the intentions of Richard Stone and his research group in the 1950s and 1960s. In this paper, we use the SNA concept of total labour costs in production - that is, the standard Marxian labour values of commodities - to reconsider his theory of surplus value as the explanation of the essential sources of profitability in a capitalist economy. We discuss the theory of surplus value from both a theoretical and an empirical viewpoint, focusing on the German economy after the reunification. Our empirical investigation is based on the dataset developed by Kalmbach et al. (2005) describing the German economy for the years 1991-2000. ${ }^{3}$ Kalmbach et al. (2005) group the 71 original sectors into seven macro-sectors. They divide the industrial sector into agriculture, manufacturing and construction. Within manufacturing itself, they further distinguish more traditional industries from the so-called 'export core' (a crucial subsector in an export-oriented country like Germany), which comprises the four single production sectors with the highest exports: chemical, pharmaceutical, machinery and motor vehicles. They also distinguish between three main types of services: business-related services, consumer services and social services. For their aggregation, Kalmbach et al. (2005) adopt a broad definition of business-related services by including wholesale trade, communications, finance, leasing, computer and related services, and research and development services, in addition to business-related services in a narrow sense. Consumer services include: retail trade, repair, transport, insurance, real estate services and personal services. Table 1 summarises the seven (macro) sectors thus obtained and the sectoral output shares (for the year 2000).

The technological coefficients of the seven-sectoral aggregation are reported in Table 2, which shows the matrix of intermediate inputs, $A$, and the vector of labour coefficients, $l$, of the German economy for the year 1995. The corresponding

3. We thank Reiner Franke for supplying us with the additional data needed for this paper. 
Table 1 The seven-sectoral structure of the German economy (percentage of total output, 2000)

\begin{tabular}{llr}
\hline S1 & Agriculture & 1.33 \\
S2 & Manufacturing (export core) & 12.37 \\
S3 & Other manufacturing & 22.55 \\
S4 & Construction & 6.29 \\
S5 & Business-related services & 21.36 \\
S6 & Consumer services & 23.35 \\
S7 & Social services & 12.75 \\
\hline
\end{tabular}

Source: Kalmbach et al. (2005).

Table 2 Technological coefficients of the seven-sectoral aggregation input-output matrix (Germany, 1995, sectors 1-7 as columns, per million euros of output value)

\begin{tabular}{llllllll}
\hline & S1 & S2 & S3 & S4 & S5 & S6 & S7 \\
\hline S1 & 0.030 & 0.000 & 0.047 & 0.000 & 0.000 & 0.002 & 0.002 \\
S2 & 0.081 & 0.241 & 0.050 & 0.021 & 0.003 & 0.008 & 0.014 \\
S3 & 0.159 & 0.226 & 0.338 & 0.286 & 0.030 & 0.060 & 0.065 \\
S4 & 0.010 & 0.005 & 0.009 & 0.020 & 0.007 & 0.034 & 0.020 \\
S5 & 0.137 & 0.107 & 0.126 & 0.088 & 0.291 & 0.118 & 0.080 \\
S6 & 0.032 & 0.044 & 0.045 & 0.100 & 0.071 & 0.139 & 0.044 \\
S7 & 0.034 & 0.008 & 0.013 & 0.007 & 0.009 & 0.014 & 0.025 \\
1 & 25.4 & 6.6 & 8.5 & 13.3 & 11.0 & 12.8 & 20.4 \\
\hline
\end{tabular}

depreciation matrix, $D$, is in Table 3. The entries of $A, l, K, D$ and $v$ are all measured per million euros of output value. ${ }^{4}$

Let $p_{n}$ be the vector of average nominal market prices in the economy. We have derived $p_{n}$ from data on nominal output levels $x_{n}$ and real output levels $x$ (based on constant prices of the year 1995).

Three characteristics of our empirical framework should be noted here, which are important in the context of value theory. First, the definition of labour values includes the depreciation matrix $D$, and therefore physical joint production can be ignored. Second, Kalmbach et al. (2005) define the average nominal wage level by dividing the sum of all wage incomes by total employment. Formally, suppose that there is a set $\{1, \ldots, T\}$ of types of workers in the economy, and let $t \in\{1, \ldots, T\}$ denote a generic type. Let $w_{n_{t j}}$ denote the nominal wage rate paid to a worker of type $t$ employed in sector $j$ and let $l_{t j}$ denote the amount of time worked by her. Then, the average nominal wage is obtained, dividing $\Sigma_{t} \Sigma_{j} w_{n_{t j}} l_{t j}$ by total employment $l x$. This implies that wage differentials are used to homogenise labour inputs when defining labour values, ${ }^{5}$

4. Note that, owing to data limitations, employment is measured in terms of workers and not in terms of hours worked. Note also that all absolute magnitudes, such as $x, y$ and $c$ below, are measured in millions of euros. For more details on measurement issues, see Kalmbach et al. (2005).

5. We believe that this is in line with what Marx (1954: 51-52) states when he refers to a social process, fixed by custom. 
Table 3 Depreciation matrix D (Germany, 1995)

\begin{tabular}{lccccccc}
\hline & S1 & S2 & S3 & S4 & S5 & S6 & S7 \\
\hline S1 & 0.0008 & 0.0002 & 0.0003 & 0.0001 & 0.0004 & 0.0006 & 0.0004 \\
S2 & 0.0455 & 0.0126 & 0.0161 & 0.0061 & 0.0233 & 0.0322 & 0.0251 \\
S3 & 0.0562 & 0.0156 & 0.0199 & 0.0075 & 0.0288 & 0.0398 & 0.0310 \\
S4 & 0.0452 & 0.0125 & 0.0160 & 0.0060 & 0.0231 & 0.0320 & 0.0249 \\
S5 & 0.0223 & 0.0062 & 0.0079 & 0.0030 & 0.0114 & 0.0158 & 0.0123 \\
S6 & 0.0090 & 0.0025 & 0.0032 & 0.0012 & 0.0046 & 0.0063 & 0.0049 \\
S7 & 0.0004 & 0.0001 & 0.0001 & 0.0000 & 0.0002 & 0.0003 & 0.0002 \\
S & 0.1793 & 0.0498 & 0.0635 & 0.0239 & 0.0918 & 0.1270 & 0.0989 \\
\hline
\end{tabular}

consistently with our theoretical focus on the aggregate wage level $w_{n}$ and on the wage share $w$.

Third, Kalmbach et al. (2005) construct the matrix $A$ using data on the industrial consumption of domestic and imported commodities. Thus $A$ provides the technological matrix of intermediate inputs irrespective of their origin. This implies that labour values are measured on the basis of the domestic technology and independently of the conditions under which the imported commodities were actually produced. This treatment is very similar to the approach pioneered by Gupta/Steedman (1971) and in our view it is a more appropriate way of dealing with international labour values than Steedman's (2008) model, in which terms of trade directly enter the definition of labour values. Our approach has two advantages: first, to measure labour values as if foreign commodities were domestically produced reduces significantly data intensity and the likelihood of measurement errors. Second, our approach is adequate if one wants to study the economy not only from the viewpoint of labour productivity, but also from a reproduction perspective where the flow relationships of actual inputs to outputs are the focus of interest, independently of whether the inputs are produced domestically or internationally. ${ }^{6}$

The notion of labour values employed in this paper is therefore specific in that we adopt a particular treatment of international trade (where domestic techniques matter, but not the origin of inputs), heterogeneous labour (where wage differentials are used to compare different skills), and fixed capital. It is, however, rather general, in the sense that it holds in a general open economy with a complex technology using fixed capital. Indeed, from a general theoretical viewpoint, if the industry-technology assumption of the UN's SNA (United Nations 1968, see also Flaschel 1983) is used in the construction of the input matrix $A$ and if the vector $l$ only contains 'productive labour' in the sense of Marx (1954), then our definition of labour values is indeed completely general; it displays no joint production/fixed capital anomalies of the type constructed by Steedman (1977); and - unlike in Steedman's (1977) approach - it is firmly based on the actual behaviour of firms (see Bródy 1970). Thus it properly reflects the strong empirical orientation of Marx's labour theory of value and its relation with agents' behaviour.

6. The role of terms of trade for calculating and comparing value and price rates of profit might be more relevant to analyse international trade and unequal exchange between countries. However, the issue of international exploitation is contentious and a proper treatment lies beyond the boundaries of this paper. For different views see, for example, Negishi (1989: 210-213) and Veneziani/Yoshihara (2012). We are grateful to an anonymous referee for alerting us to this issue. 
Table 4 Labour values or total labour costs (persons per million euros of output value)

\begin{tabular}{cccccccc}
\hline Year & S1 & S2 & S3 & S4 & S5 & S6 & S7 \\
\hline 1991 & 54.68 & 26.53 & 30.23 & 28.53 & 24.45 & 27.22 & 30.69 \\
1992 & 47.44 & 25.82 & 28.78 & 27.40 & 23.82 & 26.67 & 29.88 \\
1993 & 45.24 & 26.55 & 28.55 & 27.77 & 23.62 & 26.95 & 30.04 \\
1994 & 44.65 & 25.09 & 27.48 & 27.12 & 23.40 & 26.32 & 29.63 \\
1995 & 42.95 & 23.83 & 27.30 & 27.60 & 23.32 & 25.64 & 29.45 \\
1996 & 38.76 & 23.87 & 26.46 & 27.65 & 23.06 & 25.29 & 29.45 \\
1997 & 37.81 & 22.98 & 25.62 & 27.02 & 22.83 & 25.02 & 29.11 \\
1998 & 37.42 & 22.94 & 25.63 & 26.92 & 22.39 & 25.02 & 28.92 \\
1999 & 36.46 & 23.46 & 24.89 & 26.65 & 21.82 & 24.93 & 28.86 \\
2000 & 35.90 & 22.39 & 23.79 & 26.14 & 22.03 & 24.99 & 28.63 \\
\hline
\end{tabular}

Table 5 Capital stock matrix (Germany, 1995)

\begin{tabular}{lccccccc}
\hline & S1 & S2 & S3 & S4 & S5 & S6 & S7 \\
\hline S1 & 0.1560 & 0.0043 & 0.0055 & 0.0021 & 0.0080 & 0.0111 & 0.0086 \\
S2 & 0.3705 & 0.1028 & 0.1312 & 0.0493 & 0.1897 & 0.2625 & 0.2044 \\
S3 & 0.4959 & 0.1377 & 0.1756 & 0.0660 & 0.2539 & 0.3513 & 0.2736 \\
S4 & 0.9031 & 0.2507 & 0.3199 & 0.1202 & 0.4624 & 0.6398 & 0.4982 \\
S5 & 0.2217 & 0.0615 & 0.0785 & 0.0295 & 0.1135 & 0.1570 & 0.1223 \\
S6 & 0.0835 & 0.0232 & 0.0296 & 0.0111 & 0.0427 & 0.0591 & 0.0460 \\
S7 & 0.0074 & 0.0020 & 0.0026 & 0.0010 & 0.0038 & 0.0052 & 0.0041 \\
S & 2.0975 & 0.5823 & 0.7429 & 0.2792 & 1.0739 & 1.4861 & 1.5720 \\
\hline
\end{tabular}

Table 4 shows the time series of labour values for the Germany economy (19912000). The data clearly show that there is a tendency for labour values to fall over time in all sectors. This provides prima facie support to the law of decreasing labour content originally formulated by Farjoun/Machover (1983), which Flaschel et al. (2012b) have proved to hold under profitable capital-using labour-saving technical change - the typical form of technical change during the evolution of capitalism.

Finally, following standard practice in advanced IO analysis (see Bródy 1970), we use a capital stock matrix, $K$ (also measured per million euros of output value) in order to calculate rates of profit with respect to the capital advanced in production. The capital stock matrix for Germany in 1995 is shown in Table $5 .^{7}$

7. Note that this matrix represents 'capital advanced', which is not only so-called 'fixed capital', but also for example the average inventory of wheat in bread production (see Brody 1970: 35-37 for discussion of the turnover time of such goods). Note, moreover, that sector 7 includes all government services (including the military) as well as private social services (provided, for example, by religious organisations). Finally, note that sector 2 - at this high aggregation level - may hold inventories from agriculture and may have capital advances concerning social services, like public administration costs and more. 


\section{AVERAGE VALUE AND PRICE GROSS RATES OF PROFIT}

By definition, in every given period, the labour value of aggregate net output is equal to total direct labour performed; formally, $v y=l x$. For a given arbitrary vector of market prices, $p_{n}$, instead, no such relation holds. However, we can normalise market prices, $p_{n}$, by a factor, $\gamma$, such that the normalised value of net output is equal to the total labour time employed by firms. Formally, we let $p=\gamma p_{n}$, where $\gamma$ is such that $p y=l x$. Hence, if the average nominal wage is $w_{n}$, the wage share is given by $w=$ $\frac{w_{n} l x}{p_{n} y}=\gamma w_{n}$ and, supposing labour inputs to be paid ex post, the economy-wide gross price rate of profit is:

$$
r_{p}=\frac{(1-w) l x}{p K x}=\frac{1-w}{w} \frac{w l x}{p K x}
$$

where $e_{p}=\frac{1-w}{w}$ represents Marx's rate of exploitation according to the 'New Interpretation' (Duménil 1980; Foley 1982) and $\frac{l x}{p K x}$ is the aggregate labour-capital ratio in terms of market prices. In our empirical analysis, we assume that the structure of workers' consumption is constant throughout the period considered. Formally, we take as given the aggregate consumption vector of workers, $\tilde{c}$, and define $c=\delta \tilde{c}$, where $\delta$ is a positive number such that $p c=w\left(\right.$ or $p_{n} c=w_{n}$ ). In other words, for a given consumption structure, $c$ is the consumption vector that workers could afford at the given wage rate (setting aside savings, taxes and so on). It provides the potential (not the actual) consumption basket of workers (per unit of labour), given the relative structure of their consumption basket as contained in $\tilde{c}$. Given this normalisation, the price rate of profit can be written as $r_{p}=\frac{(1-p c) x}{p K x}$. Table 6 shows the aggregate consumption basket of German workers in the year 2000 and compares it with aggregate net output in the seven sectors.

The vector $\tilde{c}$ in Table 6 is based on data containing all household consumption (including pure capitalists). Unsurprisingly, the percentage of consumption in net output is very high in agriculture (S1) and in consumer services (S6), and it is lowest in construction (S4), which by definition produces investment goods. Although the percentage of net output consumed by workers in the business-related services sector may seem too high, this is due to the fact that the sector also contains the services of lawyers, the production of software, and other products which can also be purchased by the household sector. Note also that intermediate consumption of these products is significant as shown in Table 2 .

Table 6 Consumption vs final demand (million euros)

\begin{tabular}{lrrr}
\hline Sector & \multicolumn{1}{c}{$\tilde{c}$} & \multicolumn{1}{c}{$y$} & $\tilde{c} / y(\%)$ \\
\hline S1 & 5470.0 & 6054.8 & 90.342 \\
S2 & 36997.1 & 177601.8 & 20.832 \\
S3 & 95319.9 & 178301.5 & 53.460 \\
S4 & 2327.7 & 103454.7 & 2.250 \\
S5 & 60821.5 & 119990.0 & 50.689 \\
S6 & 481019.8 & 525536.2 & 91.529 \\
S7 & 411098.7 & 413658.3 & 99.381 \\
\hline
\end{tabular}


It is worth briefly commenting on the high percentage of consumption in net output in the social services sector. This derives from our choice to include in the vector $\tilde{c}$ all the social services consumed by the household sector, including those - such as education, health care, elderly care, administration, police, military, and even 'Christian' services - that are mainly financed through 'government' activities based on tax revenues. If we only focused on the social services directly paid for by the household sector, the percentage of consumption in net output would fall from above 90 per cent to slightly above 10 per cent. To be sure, the inclusion of government-driven consumption into the workers' consumption bundle is an open and controversial issue, from a general theoretical viewpoint. However, it turns out to be of secondary importance in the context of our analysis of aggregate profitability. For the choice of the bundle $\tilde{c}$ is relevant for the composition of the workers' reference consumption bundle, but not for consumption levels, which are instead determined by the wage. Indeed, it can be shown that our empirical results remain essentially identical if only social services directly paid for by the households are included. ${ }^{8}$ As already noted, we view labour values as a theoretical skeleton behind the surface-skin of price-quantity dynamics that is, as part of an SNA, which is designed to understand the capitalist process of economic and social reproduction. From this viewpoint, there is nothing to 'transform' when going from value expressions to price expressions, or vice versa. Rather, one should show how labour values can be used to detect the fundamental laws of motion of capitalism. From a Marxian perspective, the first and most important step is to understand the essential determinants of the average (not necessarily uniform) price rate of profit or - put differently - to what extent the generation of absolute and relative surplus value, and technical progress, drive profitability. Our next step, then, is to analyse profitability from the perspective of labour accounting.

Given the consumption bundle, $c$, the standard interpretation of Marx's theory is that the value of labour power coincides with the labour embodied in $c$, namely $v c$ (here measured in terms of workers' potential consumption). The average value rate of profit can then be defined as follows:

$$
r_{v}=\frac{v(I-A-D) x-v c l x}{v K x}=(1-v c) \frac{l x}{v K x}=\frac{1-v c}{v c} \frac{v c l x}{v K x},
$$

where $e_{v}=\frac{1-v c}{v c}$ is the standard definition of the rate of exploitation and $\frac{l x}{v K x}$ represents the labour-capital ratio in value terms. The average value rate of profit thus depends on three fundamental Marxian magnitudes: the value of labour power, $v c$; the total amount of hours worked, $l x$; and the labour value of the total capital stock, $v K x$. The value of labour power is related to what Marx called the generation of relative surplus value: a decrease in workers' wages and consumption, or technological progress lowering the value of consumption goods lowers the value of labour power and thus increases the value rate of profit. The hours actually worked by the workforce have to do with the generation of absolute surplus value, and can be increased if monthly hours worked are increased, if absenteeism is forced down, if holidays are reduced and if (not covered by the model) work intensity is increased, thus driving an increase in the value rate of profit. The labour value of the total capital stock is affected by accumulation and technical change. Accumulation tends to increase the labour value of the capital stock and thus to lower the value rate of profit. It is difficult, instead, to make clear theoretical predictions on the effect of technical change on

8. The results are available from the authors upon request. 
profitability. Flaschel et al. (2012b) have proved - in a general $m$-sectoral input-output model - that under mild assumptions, any cost-reducing innovation that substitutes fixed capital for living labour (that is, the Marxian fixed-capital-using labour-saving technical change) in a given sector decreases labour values in all sectors. Noting that capital-using labour-saving technical change has characterised most phases of capitalist development (Marquetti 2003), this result provides theoretical foundations to the law of decreasing labour content and it may explain the tendential decrease in labour costs observed in empirical studies, and forcefully shown in Table 4 above. If this law is sufficiently strong, then the reduction in labour values may outweigh the increase in the capital stock $K x$ (and the decrease in $l x$ ) thus increasing the value rate of profit. The tension between increases in the capital stock and decreases in labour values can be considered as a fundamental contradiction in the capitalist process of technical change, which is related to Marx's discussion of the role of changes in capital intensity - the so-called technical composition of capital. Whether the law of decreasing labour content is sufficiently strong to outweigh the countervailing effects is an empirical issue: in a Schumpeterian perspective, the strength of the law may depend on the phase of the long-wave under consideration. In the phase of radical process and product innovations, relatively small increases in capital intensity may yield major increases in productivity, thus lowering the labour value of the total capital stock. As the wave of innovations phases out, larger investments are required to obtain relatively smaller increases in productivity, leading the value of the total capital stock to rise.

To summarise: the basic forces driving an increase in the value rate of profit are a decrease in the value of labour power, an increase in working hours (or working intensity), and technical change leading to a significant decrease in labour values that outweighs any increase in fixed capital. Having identified the determinants of the value rate of profit, $r_{v}$, the question is whether this can help us to understand movements in the actual price rate of profit, $r_{p}$. For it is price, not value magnitudes, that are relevant for economic agents and their decisions. By Equations (2) and (3), the following relation between the price and the value rates of profit can be easily derived:

$$
\frac{r_{v}}{r_{p}}=\frac{(1-v c)}{(1-p c)} \frac{p K x}{v K x}, w=p c .
$$

If total labour costs explain the bulk of costs mirrored by actual prices, then $r_{v}$ and $r_{p}$ will be close. However, the two rates of profit will also be similar if sectoral differences cancel out in the aggregate such that both the labour value of the workers' consumption bundle is close to its monetary value, and the price and value measures of the total capital stock are similar. In this case, the theoretical value rate of profit and the actual price rate of profit would differ only by unsystematic, historically determined price-value deviations that cannot be exploited by the capitalist class as a whole, and any factors influencing the value rate will also affect the price rate of profit in the same direction. The theoretical and empirical relation between the price rate of profit, $r_{p}$, and the value rate, $r_{v}$, is arguably the fundamental topic in Marx's labour theory of value. In the next section, we investigate the empirical relation between the two rates in order to test whether the production-based rate, $r_{v}$, provides a proxy for the average price rate of profit, $r_{p}$, or at least whether there exists a robust correlation between them. The aim is to understand whether the forces underlying the evolution of $r_{v}$ also drive by and large the changes in the observed rate of profit, $r_{p}$. In this case, the Marxian theory of exploitation could be used as the foundation for an 
analysis of overall profitability, with the key determinants of the value rate also driving the dynamics of the observed rate of profit, $r_{p}$, which is the key variable of interest for the capitalist class as a whole.

\section{THREE MAIN SOURCES OF AGGREGATE PROFITABILITY}

This section provides an empirical illustration of the relation between $r_{p}$ and $r_{v}$, applying the data set constructed by Kalmbach et al. (2005). Based on a sectoral analysis, this relation is far from obvious. For, as shown in Flaschel et al. (2013), the variance of price-value ratios can be large. For example, in 1991 the vector of price-value ratios $\mu_{j}=\frac{p_{j}}{v_{j}}(j=1, \ldots, 7)$ is:

$$
\left(\mu_{1}=0.56, \mu_{2}=1.13, \mu_{3}=1.02, \mu_{4}=0.97, \mu_{5}=1.18, \mu_{6}=1.03, \mu_{7}=0.89\right) .
$$

In other words, the price-value ratio is highest in the business-related services sector and lowest in agriculture, with significant differences between values and prices also in other sectors. This pattern is persistent throughout the sample. However, as noted above, what really matters is whether sectoral deviations cancel out at the aggregate level. Table 7 shows the value and the price rate of profit, and their deviation, and it proves that indeed sectoral price-value deviations do not really matter in the aggregate. For the price rate of profit clearly mirrors the value rate of profit up to negligible deviations.

These results provide an empirical illustration of what Flaschel et al. (2013) call the 'fuzzy connection' between the average price and value rates of profit. Any sectoral deviations between market prices and labour values are in general such that they wash out at the aggregate level. ${ }^{9}$ Table 7 also shows that the average price rate of profit has fallen in 1991-1993 and in 1997-2000, possibly an effect of the cyclical fluctuations in economic activity.

An economy can be analysed from three different perspectives, focusing either on the physical flow of commodities, on nominal (price) flow magnitudes, or on abstract

Table 7 Main results

\begin{tabular}{ccccccc}
\hline Year & $w=p c$ & $v c$ & $v c / p c$ & $r_{p}(\%)$ & $r_{v}(\%)$ & $r_{v} / r_{p}$ \\
\hline 1991 & 0.698 & 0.714 & 1.02 & 14.7 & 14.3 & 0.969 \\
1992 & 0.717 & 0.730 & 1.02 & 13.3 & 13.1 & 0.979 \\
1993 & 0.728 & 0.736 & 1.01 & 12.1 & 12.0 & 0.989 \\
1994 & 0.715 & 0.724 & 1.01 & 12.8 & 12.7 & 0.989 \\
1995 & 0.714 & 0.723 & 1.01 & 12.8 & 12.5 & 0.981 \\
1996 & 0.713 & 0.720 & 1.01 & 12.8 & 12.5 & 0.981 \\
1997 & 0.699 & 0.708 & 1.01 & 13.5 & 13.2 & 0.981 \\
1998 & 0.700 & 0.710 & 1.01 & 13.4 & 13.0 & 0.970 \\
1999 & 0.706 & 0.715 & 1.01 & 13.0 & 12.7 & 0.973 \\
2000 & 0.710 & 0.724 & 1.02 & 12.8 & 12.4 & 0.965 \\
\hline
\end{tabular}

9. Actually, a number of empirical studies have identified a very strong correlation between prices and labour values even at the sectoral level. See, for example, Shaikh $(1984 ; 1998)$, Cockshott/ Cottrell (1997), Tsoulfidis/Maniatis (2002) and Fröhlich (2013). 
labour flows. Relating the labour-time oriented SNA to the flow of actually observed (quantity and price) magnitudes is not a 'transformation problem'. Rather, it provides an alternative representation of the economy, as Stahmer (2000) has convincingly argued. From this perspective, our empirical analysis shows that there exists a clear relationship, or connection, between the average price rate of profit and the average value rate of profit, which is so strong as to suggest that the Marxian concepts of absolute and relative surplus value, and his analysis of technical change and accumulation, may provide the basis for the explanation of the determinants of the average price rate of profit. The seemingly substantial sectoral price-value deviations and the strong correlation between aggregate price and value profit rates suggests - in Marxian terms that distinct processes may regulate the generation and the distribution of profits. At the aggregate level, profitability can only be improved by Marxian mechanisms: an increase in absolute surplus value $(l x \uparrow)$ or in relative surplus value $(v c \downarrow)$, and a decrease in the labour value of the capital stock - for example, due to technical change which raises labour productivity (lowers labour values $v$ ) to such a degree that it outweighs any countervailing effects on the value of the capital stock.

Examples of innovations that may lead to a decrease in the value of aggregate capital are Harrod-neutral technical change or, as mentioned above, Schumpeterian innovation waves leading to radical process and product innovations. Table 8 , however, suggests that there has been no systematic decrease in the labour value of the capital stock, $v K x$, in the German economy during 1991-2000, although labour productivity $\frac{1}{v_{j}}(j=1, \ldots, 7)$ increased. ${ }^{10}$

Two last points are worth making concerning our results, and in particular the ratios shown in Tables 7 and 8. First, the labour value of the workers' consumption basket has always been greater than its price equivalent, the labour value of the capital stock has always been smaller than its price equivalent, and the value rate of profit has always been smaller than the price rate of profit. From our point of view, there is no obvious explanation for these phenomena. Second, however, it is worth stressing again the remarkably strong relations between aggregate value and price magnitudes: the differences between value and price expressions of profitability, aggregate capital

Table 8 Employment, labour value of capital stock, price value of capital stock, and relative value of capital stock (measured in million persons)

\begin{tabular}{ccccc}
\hline Year & $l x$ & $v K x$ & $p K x$ & $v K x / p K x$ \\
\hline 1991 & 38.45 & 77.13 & 78.89 & 0.9777 \\
1992 & 37.88 & 78.35 & 80.51 & 0.9731 \\
1993 & 37.37 & 82.18 & 83.81 & 0.9805 \\
1994 & 37.30 & 81.21 & 83.14 & 0.9768 \\
1995 & 37.38 & 82.48 & 83.52 & 0.9876 \\
1996 & 37.27 & 83.37 & 83.87 & 0.9941 \\
1997 & 37.21 & 82.35 & 83.16 & 0.9902 \\
1998 & 37.61 & 84.27 & 84.51 & 0.9971 \\
1999 & 38.08 & 85.61 & 85.80 & 0.9978 \\
2000 & 38.76 & 86.45 & 87.82 & 0.9844 \\
\hline
\end{tabular}

10. See Table 4. 
and workers' purchasing power are negligible. Thus, among other things, Tables 7 and 8 suggest that it may be immaterial, from an empirical viewpoint, whether one defines the value of labour power as the labour embodied in the workers' normalised (potential) consumption bundle, $v c$, or by equating it to the wage share, $w$, as in the so-called 'New Interpretation' (Duménil 1980; Foley 1982). Indeed, in a companion paper (Flaschel et al. 2013), we have shown that the price rate of profit and the value rate of profit coincide up to negligible deviations, even if one adopts the definition of the value of labour power of the 'New Interpretation'. ${ }^{11}$ These remarkable regularities suggest that theoretical distinctions between alternative approaches to Marxian value theory may turn out to be irrelevant at the empirical level.

\section{CONCLUSIONS}

This paper provides an empirical analysis of value and price profit rates in the German economy (1991-2000) based on an input-output theoretic interpretation of labour values. In our approach, labour magnitudes are part of an SNA designed to understand the laws of development of capitalist economies behind the surface of nominal magnitudes. Our empirical results show that there indeed exists a very strong relation between (aggregate) price and value magnitudes - especially between the economywide value and price profit rates. Thus Marx's theory of exploitation may provide the foundations for an understanding of profitability in a capitalist economy, and systematic changes in profitability can be analysed by focusing on labour value magnitudes which are more informative than the corresponding price expressions, due to the 'chaotic' nature of the processes of commodity exchange in space and time. The three key mechanisms highlighted in Marx's theory of exploitation are central in determining profitability for the capitalist class as a whole: the production of absolute and relative surplus value, and the capitalist laws of technical change and accumulation. In a capitalist economy, aggregate profitability can be increased by increasing total labour hours worked (or the intensity of work), or by reducing the value of labour power; or by introducing innovations that significantly increase labour productivity.

\section{REFERENCES}

Bródy, A. (1970): Proportions, Prices and Planning, Amsterdam: North Holland.

Cockshott, W.P., Cottrell, A. (1997): Labour time versus alternative value bases: a research note, in: Cambridge Journal of Economics, 21, 545-549.

Duménil, G. (1980): De la Valeur aux Prix de Production, Paris: Economica.

Farjoun, E., Machover, M. (1983): Laws of Chaos, London: Verso Edition and NLB.

Flaschel, P. (1983): Actual labor values in a general model of production, in: Econometrica, 51, 435-454.

Flaschel, P., Franke, R., Veneziani, R. (2012): Labor productivity and the law of decreasing labor content, in: Cambridge Journal of Economics, 37(2), 379-402.

Flaschel, P., Fröhlich, N., Veneziani, R. (2013): The sources of profitability, in: Taylor, L., Rezai, A., Michl, T. (eds), Social Fairness and Economics - Economic Essays in the Spirit of Duncan Foley, London: Routledge, 199-212.

11. Adopting the 'New Interpretation', however, we find that the value rate of profit is always greater than the price rate. 
Foley, D.K. (1982): The value of money, the value of labor power and the Marxian transformation problem, in: Review of Radical Political Economics, 14, 37-47.

Fröhlich, N. (2013): Labour values, prices of production and the missing equalization of profit rates: evidence from the German economy, in: Cambridge Journal of Economics, 37(5), $1107-1126$.

Gupta, S., Steedman, I. (1971): An input-output study of labour productivity in the British economy, in: Oxford Bulletin of Economics and Statistics, 33, 21-34.

Kalmbach, P., Franke, R., Knottenbauer, K., Krämer, H. (2005): Die Interdependenz von Industrie und Dienstleistungen - Zur Dynamik eines Komplexen Beziehungsgeflechts, Berlin: Edition Sigma.

Marquetti, A. (2003): Analyzing historical and regional patterns of technical change from a classical-Marxian perspective, in: Journal of Economic Behavior and Organization, 52, 191-200.

Marx, K. (1954): Capital: A Critique of Political Economy, Vol. I, London: Lawrence \& Wishart.

Mohun, S. (2004): The labour theory of value as foundation for empirical investigations, in: Metroeconomica, 55, 65-95.

Negishi, T. (1989): History of Economic Theory, Amsterdam: North Holland.

Shaikh, A. (1984): The transformation from Marx to Sraffa, in: Mandel, E., Freeman, A. (eds), Ricardo, Marx, Sraffa: The Langston Memorial Volume, London: Verso, 43-84.

Shaikh, A. (1998): The empirical strength of the labour theory of value, in: Bellofiore, R. (ed.), Marxian Economics: A Reappraisal, vol. 2, London: Macmillan, 225-251.

Stahmer, C. (2000): The magic triangle of input-output tables, in: Simon, S., Proops, J. (eds), Greening the Accounts, Cheltenham: Edward Elgar, 155-180.

Steedman, I. (1977): Marx after Sraffa, London: NLB.

Steedman, I. (2008): Marx after Sraffa and the open economy, in: Bulletin of Political Economy, 2, 165-174.

Tsoulfidis, L., Maniatis, T. (2002): Values, prices of production and market prices: some more evidence from the Greek economy, in: Cambridge Journal of Economics, 26, 359-369.

United Nations (1968): A System of National Accounts, New York: Studies in Methods, Series F, No. 2, Rev. 3.

Veneziani, R., Yoshihara, N. (2011): Strong subjectivism in the Marxian theory of exploitation: a critique, in: Metroeconomica, 62, 53-68.

Veneziani, R., Yoshihara, N. (2012): Globalisation and inequality: a dynamic general equilibrium model of unequal exchange, mimeo, Queen Mary University of London.

Yoshihara, N. (2010): Class and exploitation in general convex cone economies, in: Journal of Economic Behavior \& Organization, 75, 281-296. 